\title{
(a) UNIVERSITAS
}

hll Miguel WHernández Grupo AEAS

Rocamora Osorio, C., Abadía Sánchez, R., Melián Navarro, A., Puerto Molina, H. Hernández García, F.

Escuela Politécnica Superior de Orihuela. Universidad Miguel Hernández.

Ctra. de Beniel, km. 3,2 - 03312 Orihuela (Alicante). e-mail: rocamora@umh.es

\section{INTRODUCCIÓN Y OBJETIVOS}

El regadío tradicional de la Vega Baja del Segura es de origen romano, aunque apenas se conservan vestigios de obras de fábrica de esta época (Gil Olcina y Morales Gil, 1992). Tras la ocupación árabe se consolidó y organizó tal y como se conoce hoy, tanto en la infraestructura como en el sistema de reparto (Pérez, 1995). La superficie bruta de riego asciende a 22.872 ha

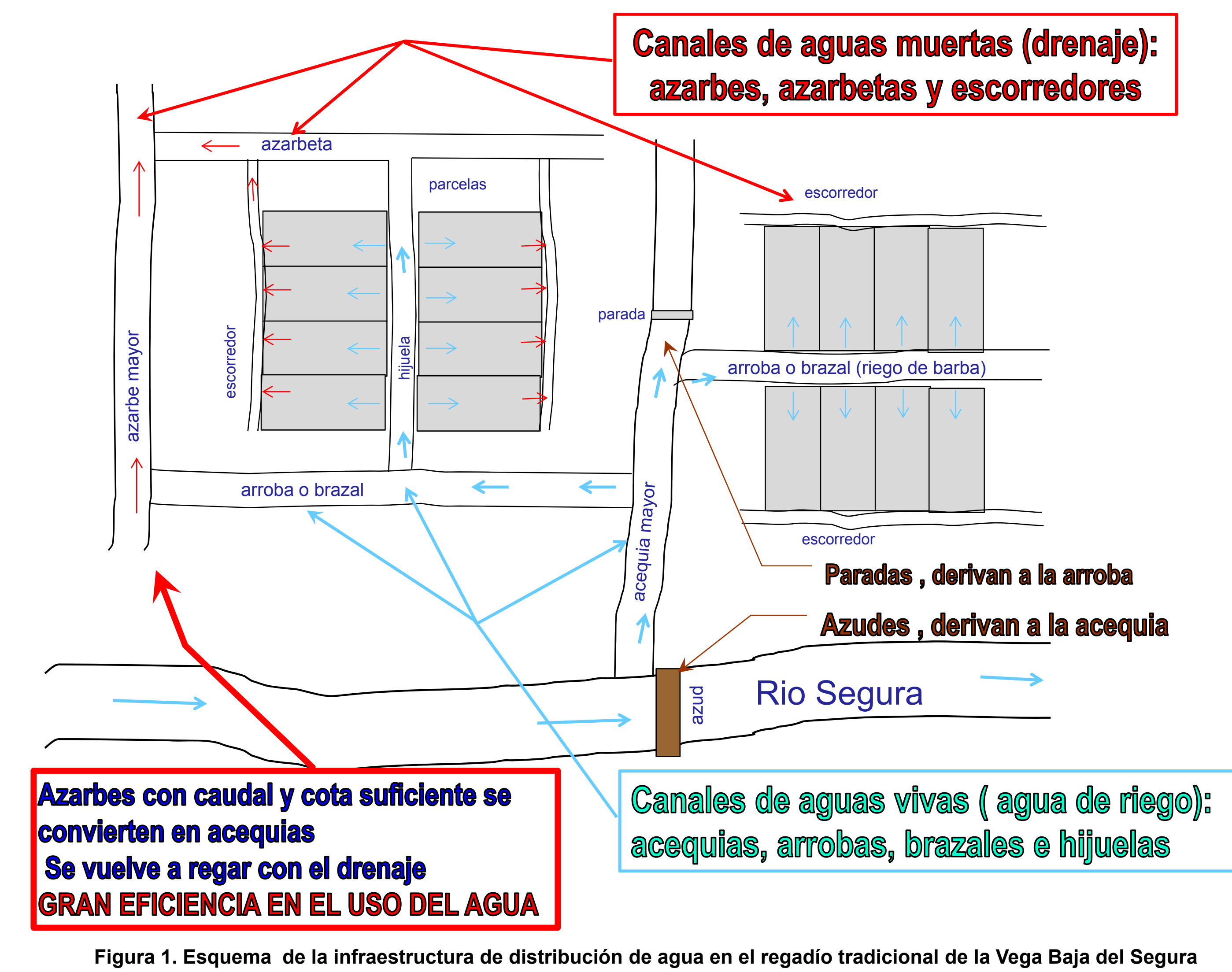

El reparto de agua se hace en base a la tanda de la acequia.

La tanda es el tiempo en que tarda en producirse el riego en toda la longitud de la acequia y está dividida en turnos fijos asignados a cada parada.

En el turno se establece un número determinado de horas de riego, pudiendo regar sólo durante las horas que tiene asignadas en el entande de la acequia.

La duración del turno no guarda una relación directa con la superficie que abastece la parada: en ocasiones proviene de antiguos privilegios, dando lugar a tierras con diferentes dotaciones.

El agua de riego está adscrita a la tierra, quedando reflejados los derechos de agua en las escrituras de propiedad de la tierra, lo que ocasiona diferencias muy importantes entre parcelas, según los derechos de agua que la parcela posea.

El sistema de aplicación de agua de riego en parcela es por inundación, en donde el exceso de agua aportado es drenado a través de la red de canales de aguas muertas. Este sistema de reparto de agua hace que en muchos casos no se haya podido desarrollar una agricultura competitiva, debido a la falta de seguridad que tienen algunas tierras para recibir la dotación completa de agua de riego. Esta situación se ve agravada por la infradotación habitual de agua de riego en toda la cuenca del río Segura,

La modernización del regadío tradicional en la Vega Baja del Segura Desde principios de los años 90 se ha tratado de poner en marcha diversos planes de modernización que no han terminado de cristalizar.

La transformación a sistemas de riego por goteo únicamente se ha producido en algunas zonas, ejecutando pequeñas redes a presión, que conviven con el sistema de reparto tradicional, o bien transformando el sistema de riego en parcela. Esta dificultad de implementación del riego a presión se debe, entre otras, a las siguientes causas:

- Necesidad de construir balsas de almacenamiento perdiendo superficie de cultivo

Dependencia de energía eléctrica para presurizar la red de distribución.

Pérdida de calidad de la producción percibida por los agricultores en determinados cultivos, como la alcachofa.

En el regadío tradicional no se paga por el agua, sino por el mantenimiento de la infraestructura, lo que no ocurre en el riego a presión.

Pérdida de valor ambiental del ecosistema agrícola que se produciría al detraer el agua del rio para transportarla por las redes a presión.

A pesar estas dificultades, el mantenimiento de la actividad agraria en la comarca es fundamental porque:

- supone mantener un paisaje funcional como es la huerta

permite absorber a parte de la población desempleada y asegura la independencia alimentaria del territorio y su abastecimiento (Cases y Marroquí, 2011).

a modernización del regadío en torno a su eje principal, el río Segura, es una actuación necesaria que debe ser acometida de forma conjunta en toda la comarca y debe plantearse como una oportunidad que permita no solo consolidar la actividad agrícola como seña de identidad de la comarca, sino la puesta en valor de su rico patrimonio material e inmaterial, como el patrimonio hidráulico, la arquitectura popular, el paisaje cultural, el ecosistema agrícola, los conocimientos agrícolas, las tradiciones etc. que deben potenciarse para asegurar el sostenimiento de la población y el progreso de la comarca. El proceso debe plantearse de forma integradora entre todos los usos que han de beneficiarse de la modernización y que, en muchos casos, tienen intereses contrapuestos, por lo que se debe valorar el proceso desde un punto de vista pluridisciplinar.

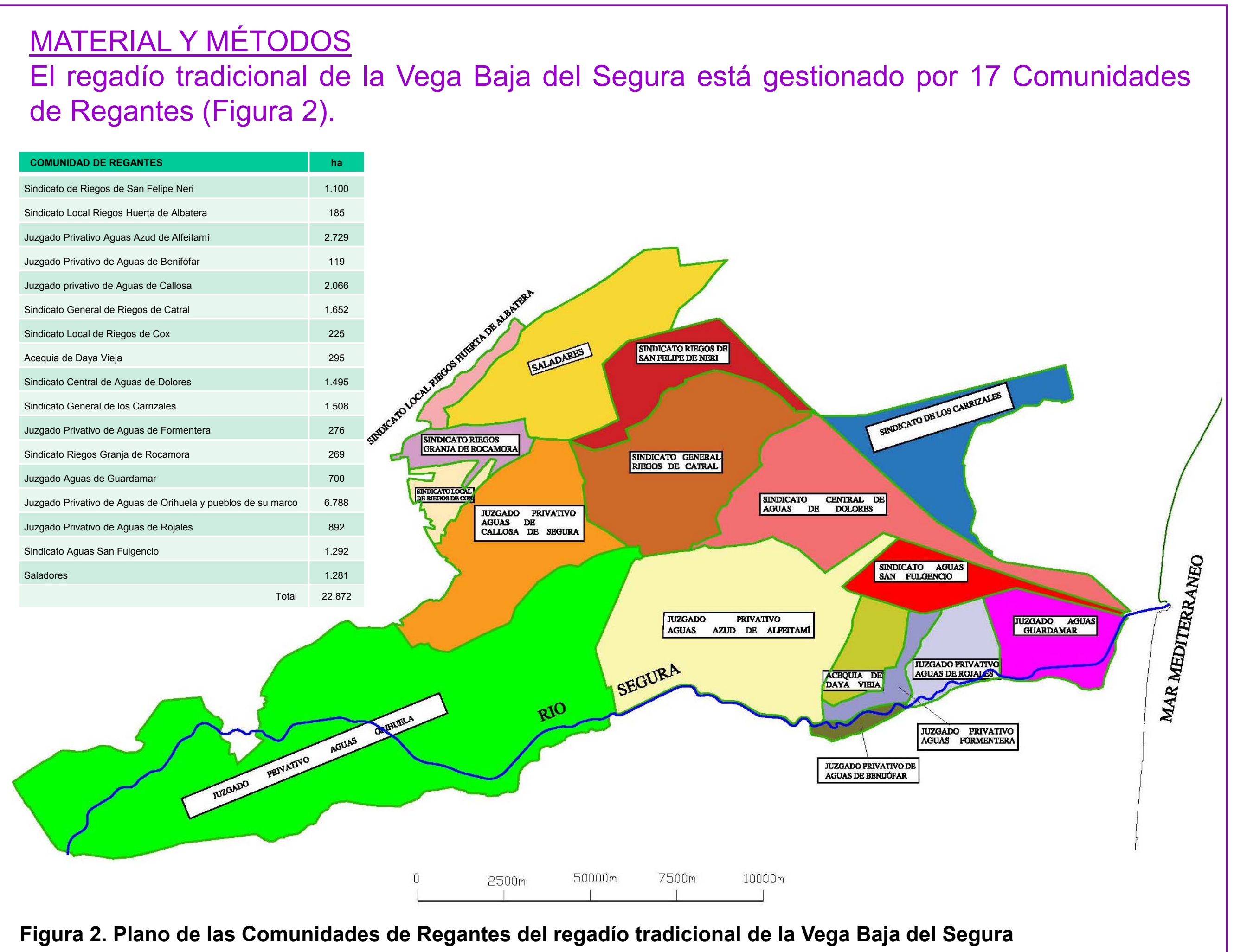

Mediante una encuesta a usuarios del regadío tradicional se analiza la percepción que tienen los agricultores de la modernización y de la repercusión que dichas actuaciones tendrían en su explotación. De las encuestas se deducen cuáles son las mejoras en el regadío que demandan los usuarios. Se plantearon las siguientes 4 alternativas:

\begin{tabular}{|c|c|c|}
\hline $\mathrm{A} 1$ & A3 & $\mathrm{A} 4$ \\
\hline $\begin{array}{l}\text { - Rehabilitar la red actual } \\
\text { de acequias } \\
\text { - Sin modificar las tandas } \\
\text { ni los turnos de riego } \\
\text { - Mantener la dotación de } \\
\text { agua a todas las } \\
\text { parcelas } \\
\text { - Mínima actuación. }\end{array}$ & \multirow{3}{*}{$\begin{array}{l}\text { - Sustituir acequias por } \\
\text { tuberías a presión } \\
\text { abastecidas del río } \\
\text { Segura } \\
\text { - Conectar el riego por } \\
\text { goteo directamente a } \\
\text { la nueva red de } \\
\text { tuberías a presión. } \\
\text { - Mantener activo el rio } \\
\text { Segura y parte de la } \\
\text { red de acequias } \\
\text { - Mantener la gestión } \\
\text { independiente de los } \\
\text { Juzgados de Agua. } \\
\text { - Costes de bombeo } \\
\text { asociados al riego. }\end{array}$} & \multirow{3}{*}{$\begin{array}{l}\text { - Sustituir las acequias por tuberías } \\
\text { a presión abastecidas del Post- } \\
\text { trasvase Tajo-Segura } \\
\text { - Conectar el riego por goteo } \\
\text { directamente a la red de tuberías } \\
\text { a presión, sin consumo energético } \\
\text { asociado al riego. } \\
\text { - El Rio Segura solo llevaría el } \\
\text { caudal ambiental; las acequias } \\
\text { dejarían de transportar agua de } \\
\text { riego. } \\
\text { - Modificar la gestión de Juzgados } \\
\text { de Agua, agrupando éstos en } \\
\text { varios sectores hidráulicos } \\
\text { - Los Juzgados de Aguas y } \\
\text { Sindicatos de Riegos compartirían } \\
\text { la infraestructura y la gestión del } \\
\text { riego. }\end{array}$} \\
\hline $\mathrm{A} 2$ & & \\
\hline $\begin{array}{l}\text { - Rehabilitar la red actual } \\
\text { de acequias } \\
\text { - Modificar los turnos de } \\
\text { riego } \\
\text { - Dotación de agua } \\
\text { proporcional a la } \\
\text { superficie de cada } \\
\text { parcela. }\end{array}$ & & \\
\hline
\end{tabular}

\section{RESULTADOS}

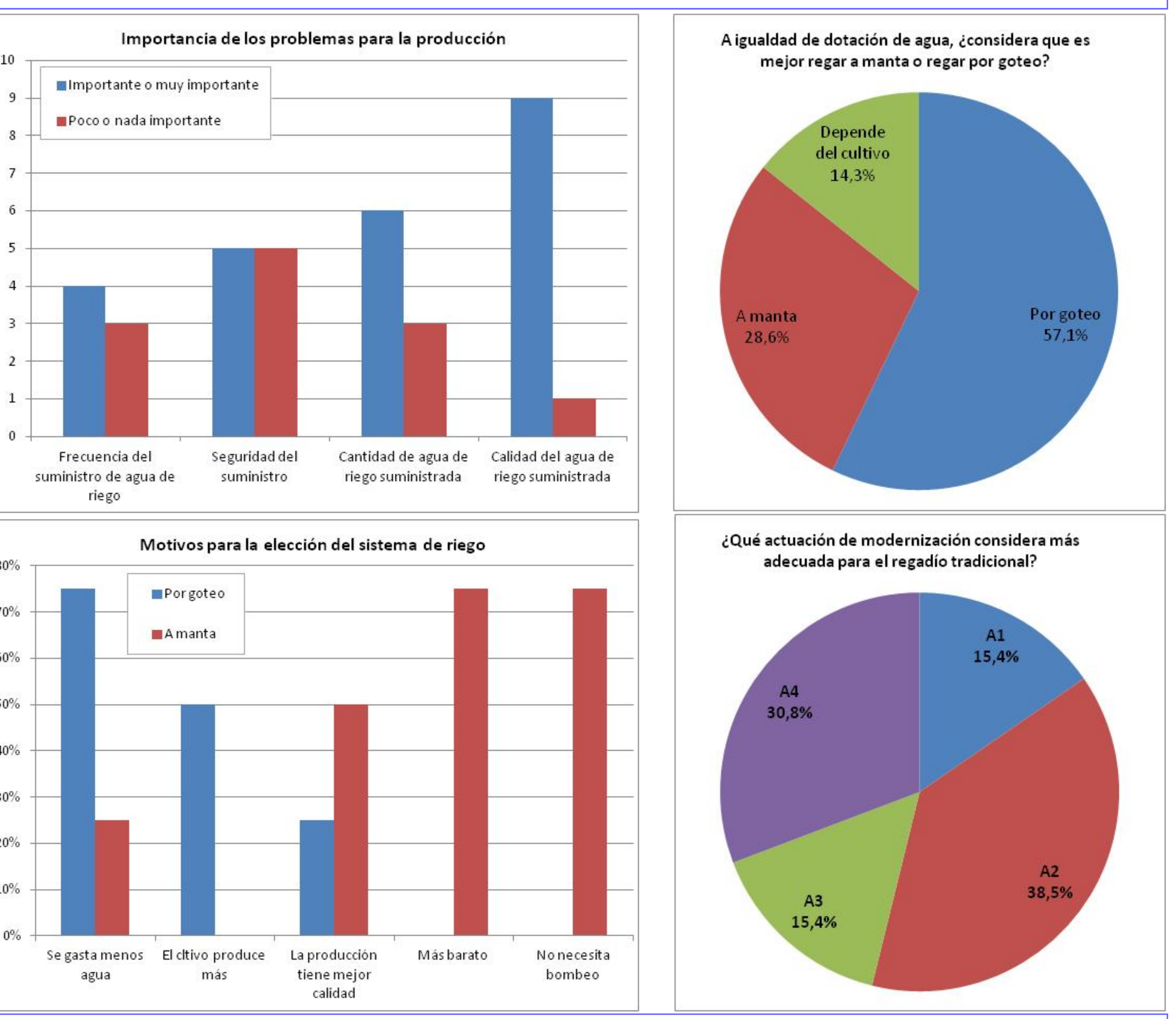

\section{CONCLUSIONES}

- A pesar de que se estima que el riego por goteo tiene ventajas y es preferible a la hora de regar si se mantiene la dotación de riego, el mantener el regadío tradicional, con o sin mejoras en los turnos de riego, ha sido la opción mayoritaria con casi el 54\% de las 